Article

\title{
Comparison of Dissolved Gases in Mineral and Vegetable Insulating Oils under Typical Electrical and Thermal Faults
}

\author{
Chenmeng Xiang ${ }^{1}$, Quan Zhou ${ }^{1}$, Jian Li ${ }^{1, *}$, Qingdan Huang ${ }^{2}$, Haoyong Song ${ }^{2}$ and \\ Zhaotao Zhang ${ }^{3}$ \\ 1 The State Key Laboratory of Power Transmission Equipment and System Security and New Technology, \\ College of Electrical Engineering, Chongqing University, Chongqing 400044, China; \\ xiangchenmeng@cqu.edu.cn (C.X.); zhouquan@cqu.edu.cn (Q.Z.) \\ 2 Guangzhou Power Supply Company, Guangzhou 510620, China; 13560381038@163.com (Q.H.); \\ songhaoyong1208@163.com (H.S.) \\ 3 State Grid Chongqing Changshou Power Supply Company, Chongqing 401220, China; zzt7933@163.com \\ * Correspondence: lijian@cqu.edu.cn; Tel.: +86-23-6510-2437
}

Academic Editor: Issouf Fofana

Received: 15 February 2016; Accepted: 18 April 2016; Published: 25 April 2016

\begin{abstract}
Dissolved gas analysis (DGA) is attracting greater and greater interest from researchers as a fault diagnostic tool for power transformers filled with vegetable insulating oils. This paper presents experimental results of dissolved gases in insulating oils under typical electrical and thermal faults in transformers. The tests covered three types of insulating oils, including two types of vegetable oil, which are camellia insulating oil, Envirotemp FR3, and a type of mineral insulating oil, to simulate thermal faults in oils from $90{ }^{\circ} \mathrm{C}$ to $800{ }^{\circ} \mathrm{C}$ and electrical faults including breakdown and partial discharges in oils. The experimental results reveal that the content and proportion of dissolved gases in different types of insulating oils under the same fault condition are different, especially under thermal faults due to the obvious differences of their chemical compositions. Four different classic diagnosis methods were applied: ratio method, graphic method, and Duval's triangle and Duval's pentagon method. These confirmed that the diagnosis methods developed for mineral oil were not fully appropriate for diagnosis of electrical and thermal faults in vegetable insulating oils and needs some modification. Therefore, some modification aiming at different types of vegetable oils based on Duval Triangle 3 were proposed in this paper and obtained a good diagnostic result. Furthermore, gas formation mechanisms of different types of vegetable insulating oils under thermal stress are interpreted by means of unimolecular pyrolysis simulation and reaction enthalpies calculation.
\end{abstract}

Keywords: vegetable insulating oil; electrical fault; thermal fault; dissolved gas analysis (DGA); fault diagnosis; gas formation mechanism

\section{Introduction}

Dissolved gas analysis (DGA) is an important and successful tool to detect incipient faults of oil-filled transformers [1]. Several interpretation methods for DGA, including the ratio methods, the graphic methods, and Duval Triangle or Pentagon methods, are available to identify the different types of faults occurring in operating transformers [2-7].

The vegetable insulating oil in transformers are applied more and more widely [8]. It has already been used in distribution transformers, and the next objective is to extend its use to HV power transformers [9]. It has different compositions between vegetable insulating oil and mineral insulating oil. Vegetable oil consists of hundreds of triglycerides, while mineral oils are mixtures of alkane, cyclones, and aromatic hydrocarbons containing carbon and hydrogen linked together by single and 
double bonds [10,11]. In addition, different types of vegetable insulating oils are also composed of different kinds and proportions of triglyceride molecules. Thus, there are differences in the variety and proportion of gas production among different types of insulating oils [12].

At present, investigations on comparisons of DGA between vegetable and mineral oils have attracted lots of interests of researchers. Martin et al. analyzed dissolved gas levels of a normally-operating power transformers filled with FR3 and indicate that ethane and hydrogen are significantly elevated compared to the same transformers filled with mineral oil [13]. However, since there is a significant lack of fault data of vegetable oil-filled transformers in service, several results of dissolved gases in vegetable oils obtained by laboratory tests. [14-18] concluded that vegetable oil and mineral oil have different dissolved gas characteristics under electrical and thermal faults. Several diagnostic methods, such as the Dornenburg method [15], IEC 60599 method [15], Roger's ratio method [15,16], and classical Duval Triangle method [15-18], which are used for diagnosing the fault type of transformers filled with mineral oil, exist limitations to diagnose the fault of transformers filled with vegetable oils directly. Thus, new versions of the Duval triangle method (Duval Triangle 3) applied to equipment filled with non-mineral oils (silicone, Midel, FR3, and Bio Temp) have been proposed [19]. Furthermore, another modified Duval triangle method (Duval Triangle 6) aiming at the stray gassing diagnosis of FR3 oil-filled transformers has been put forward [20].

According to the aforementioned publications, until now, only a few methods, such as the modified Duval triangle (Duval Triangle 3 and 6), are utilized to identify faults in vegetable oil-filled transformers. The international standard IEEE C57.155-2014 [21] provides the DGA guide application for natural and synthetic ester-immersed transformers. However, previous studies pay more attention on the comparison of dissolved gases between mineral oils and natural or synthetic esters, much less effort is involved in the comparative studies of vegetable insulating oils with different chemical compositions. Due to the fact that different vegetable oils are formed by different kinds and proportions of triglyceride molecules, the dissolved gas characteristics have some differences. Thus, there is a need to verify and improve the DGA diagnostic methods used for FR3 oils to apply it to other vegetable oils. Moreover, it is necessary to study the gas formation mechanism of different vegetable oils and this will help to provide a theoretical basis for designing diagnostic methods of vegetable insulating oils with different chemical compositions.

This work is motivated by problems posed in the present publications for future applications. Experiments simulating typical thermal and electrical faults in transformers are proposed in this paper. Gases dissolved in two types of vegetable insulating oils (FR3 oil and camellia oil) and one mineral oil are analyzed by gas chromatography, the content and proportion of fault gases in three types of insulating oils are compared with each other, the main gas compositions in two types of vegetable insulating oils of different fault types are examined. Three ratio methods, the graph representation method, Duval's Triangle method in the IEC standard [22], and the Duval pentagon method, are used to interpret experiment data, the applicability of these methods to vegetable insulating oil-filled transformers are analyzed. Furthermore, Duval's Triangle 3, which is used for the diagnosis of FR3 oils, is applied to verify the applicability of fault diagnosis in FR3 oils and camellia oils, some modifications of Duval's Triangle 3 aiming at camellia oils are also put forward. Finally, the gas formation mechanism of vegetable insulating oils based on the technique of molecular simulation and reaction enthalpies calculation is proposed in this paper.

\section{Experiment}

\subsection{Preparation and Pretreatment of Samples}

A conventional naphthenic-based mineral insulating oil, a kind of commercial soybean-based insulating oil (FR3), and a kind of camellia-based vegetable insulating oil were used in the experiment. The camellia insulating oil was obtained from camellia oil after three refinement procedures, which are alkaline refinement, vacuum distillation, and bleaching. The basic physical, chemical, and electrical 
properties of the camellia insulation oil are shown in Table 1. The related properties of the FR3 and mineral insulating oil are also presented.

Table 1. Basic physical, chemical, and electrical properties of the three types of insulation oils.

\begin{tabular}{cccc}
\hline Parameter & Camellia Oil & FR3 Oil [23] & Mineral Oil \\
\hline Appearance & Light Yellow & Light Green & Transparent \\
\hline Density $\left(20^{\circ} \mathrm{C}\right) / \mathrm{kg} \cdot \mathrm{m}^{-3}$ & 0.90 & 0.92 & $<0.895$ \\
Viscosity $\left(40{ }^{\circ} \mathrm{C}\right) / \mathrm{mm}^{2} \cdot \mathrm{s}^{-1}$ & 39.9 & 34.1 & $\leqslant 13.0$ \\
Pour point $/{ }^{\circ} \mathrm{C}$ & -28 & -21 & $<-22$ \\
Flash point $/{ }^{\circ} \mathrm{C}$ & 322 & 316 & $\geqslant 135$ \\
Acid value $/ \mathrm{mgKOH} \cdot \mathrm{g}^{-1}$ & 0.03 & 0.04 & $\leqslant 0.03$ \\
Interfacial tension $/ \mathrm{mN} \cdot \mathrm{m}$ & 25 & 24 & $\geqslant 40$ \\
AC breakdown voltage $/ \mathrm{kV}$ & 70 & 56 & $\leqslant 0.1$ \\
Dissipation factor $\left(90{ }^{\circ} \mathrm{C}\right) / \%$ & 0.88 & 0.89 & $7 \times 1011 / 25^{\circ} \mathrm{C}$ \\
Volume resistivity $/ \Omega \cdot \mathrm{m}$ & $1 \times 1010 / 90{ }^{\circ} \mathrm{C}$ & $2 \times 1011 / 25^{\circ} \mathrm{C}$ & $2.2 / 90{ }^{\circ} \mathrm{C}$ \\
Relative permittivity & $2.9 / 90{ }^{\circ} \mathrm{C}$ & $3.2 / 25^{\circ} \mathrm{C}$ &
\end{tabular}

The insulating oil and insulating paper were dried under a vacuum of $50 \mathrm{~Pa}$ for $72 \mathrm{~h}$ at $90^{\circ} \mathrm{C}$. The moisture contents of oil was examined by the Karl Fischer titration method, the moisture contents of mineral, FR3, and camellia oils were $8 \mathrm{ppm}, 36 \mathrm{ppm}$, and $29 \mathrm{ppm}$, respectively. The insulating paper was impregnated in insulating oils under a vacuum of $50 \mathrm{~Pa}$ for $24 \mathrm{~h}$ at $40^{\circ} \mathrm{C}$.

\subsection{Experimental Setup}

\subsubsection{Thermal Stress Simulation}

According to IEC 60599-2007 [22], thermal faults are classified into three groups (T1 $<300{ }^{\circ} \mathrm{C}$, $300{ }^{\circ} \mathrm{C}<\mathrm{T} 2<700{ }^{\circ} \mathrm{C}$, and $\mathrm{T} 3>700{ }^{\circ} \mathrm{C}$ ) according the temperature ranges of faults. Since the research was intended to simulate the thermal fault in transformers and analyze proportions of dissolved gases in different types of insulating oils under the same fault condition, thermal tests were carried out with and without insulating paper through setting the oven temperature at 90, 120, 150, 200, 300, 400, 500, 600,700 , or $800^{\circ} \mathrm{C}$.

In this experiment, thermal faults at temperatures below $300^{\circ} \mathrm{C}\left(90^{\circ} \mathrm{C}, 120^{\circ} \mathrm{C}, 150^{\circ} \mathrm{C}, 200^{\circ} \mathrm{C}\right.$, and $250^{\circ} \mathrm{C}$ ) were simulated in sealed glass bottles and heated uniformly in an air circulating oven [14-16]. There was a thermocouple sensor next to the sealed glass to reflect the oil temperature.

For high-temperature thermal faults, due to the high pressure in containers at high temperature, the air circulating oven could not simulate the thermal faults above $300{ }^{\circ} \mathrm{C}$. In addition, currently, some publications applied the method of heating wires in oil to simulate overheating faults [24,25]; however, it was not easy to make fault point temperatures reach above $700{ }^{\circ} \mathrm{C}$ ( $\mathrm{T} 3$ region) because of the limitation of the maximum power source and meltdown of heating wire as presented in these papers. The highest temperature that the heating wire can achieve was $600^{\circ} \mathrm{C}$ in [24] and the experimental simulating temperature was $280^{\circ} \mathrm{C}$ in [25]. In order to simulate high-temperature thermal faults and obtain fault gas data at high temperature, a specially-designed experiment system containing a pipe heater, a L-shaped stainless steel container, and a temperature controller were designed to simulate thermal faults at temperatures above $300{ }^{\circ} \mathrm{C}\left(300^{\circ} \mathrm{C}, 400{ }^{\circ} \mathrm{C}, 500{ }^{\circ} \mathrm{C}, 600^{\circ} \mathrm{C}, 700{ }^{\circ} \mathrm{C}\right.$, and $\left.800^{\circ} \mathrm{C}\right)$, as shown in Figure 1. There was a thermocouple sensor processed by means of heat insulation and contacting the surface of pipe to reflect the approximate temperature of oil. In practical situations, overheating faults at high temperature will only take place at one point in the transformer, fault gases are generated at the fault point, and then diffuse to the entire oil tank, and this is why samples used in DGA are extracted from the oil drain valve instead of the fault point. In this simulation system, $30 \mathrm{~mL}$ oil added to the pipe heater were heated, and fault gases diffused to $0.5 \mathrm{~L}$ of oil added to the stainless steel container. 


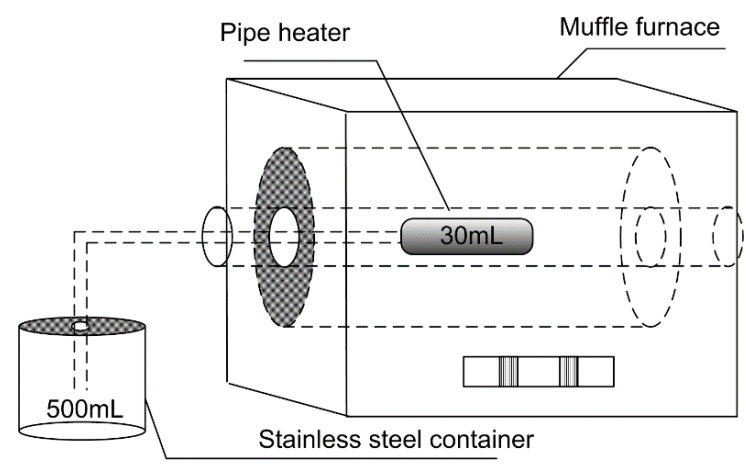

Figure 1. Sketch of thermal faults simulation system.

In order to ensure the $30 \mathrm{~mL}$ oil samples achieve the setting temperatures, the oil temperature rising process and rate were simulated before the tests.

The governing equation about the heat conduction is as follows:

$$
\left\{\begin{array}{l}
\rho c_{p} \frac{\partial T}{\partial t}+\rho c_{p} \mathbf{u} \cdot \nabla T+\nabla \cdot \mathrm{q}=Q+Q_{p}+Q_{v d} \\
\mathrm{q}=-k \nabla T
\end{array}\right.
$$

where $c_{\mathrm{p}}$ is the specific heat capacity of material, $\rho$ is the density of material, $k$ is the thermal conductivity of material, $Q$ is the conduction heat, $Q_{p}$ is the convection heat, and $Q_{v d}$ is the radiation heat.

The boundary condition is as follows:

$$
\left\{\begin{array}{c}
-n \cdot \mathrm{q}=0 \\
T=T_{0}
\end{array}\right.
$$

where $T_{0}$ is the temperature of boundary.

Figure 2 shows the temperature distribution of oil samples after heating different times when the oven temperature is $800{ }^{\circ} \mathrm{C}$.

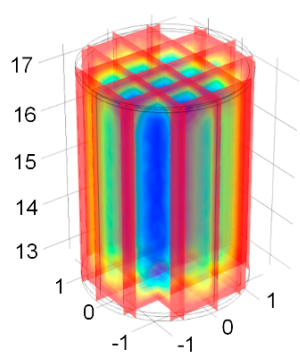

(a)

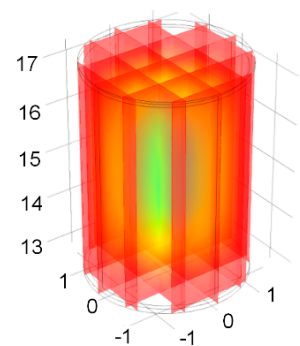

(c)
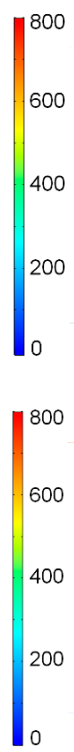

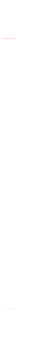

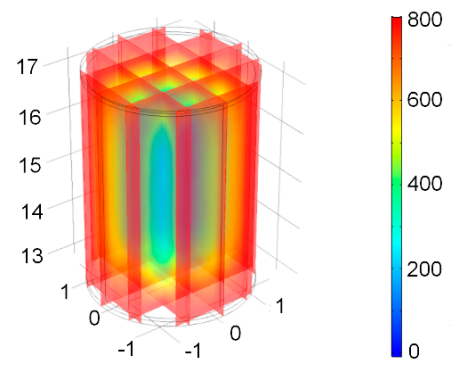

(b)

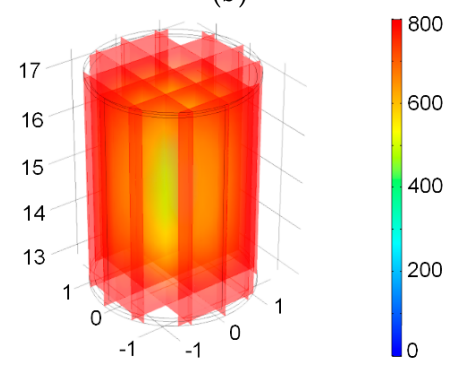

(d)

Figure 2. Temperature distribution of oil sample after heating different times when the oven temperature is $800^{\circ} \mathrm{C}$. (a) After heating $0.5 \mathrm{~min}$; (b) After heating $1 \mathrm{~min}$; (c) After heating $1.5 \mathrm{~min}$; and (d) After heating 2 min. 
Figure $3 a, b$ show the average temperature rising curve of mineral oil and vegetable oil, respectively. It is obvious that the temperature can approximately reach $800{ }^{\circ} \mathrm{C}$ during the heating time.

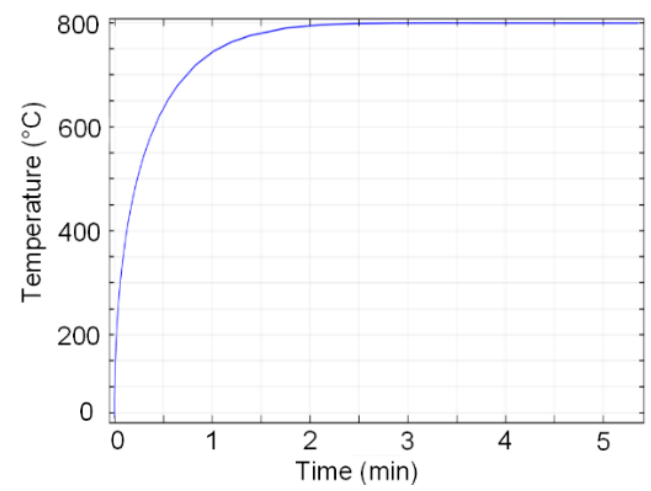

(a)

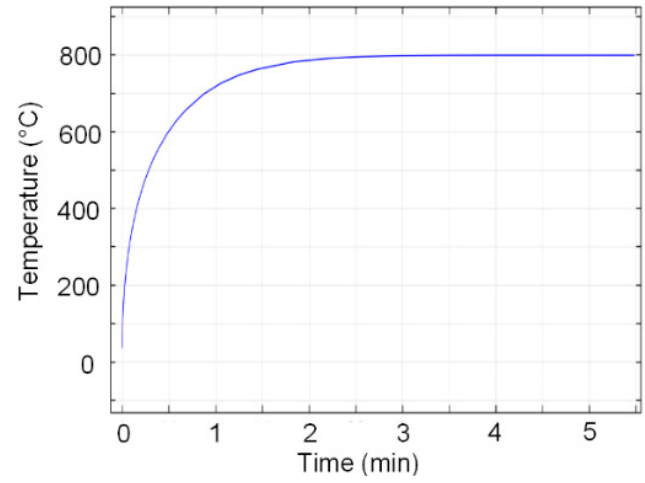

(b)

Figure 3. Temperature rising rate curve of mineral and vegetable oil samples: (a) Mineral oil; (b) Vegetable oil.

Table 2 presents the time of heating duration before the mineral oil and vegetable oil can reach the required temperature from $300{ }^{\circ} \mathrm{C}$ to $800{ }^{\circ} \mathrm{C}$. It can be seen that the oil can reach or approach the required temperature before heating of the oil stops.

Table 2. Duration of mineral and vegetable oil samples before reaching required temperatures.

\begin{tabular}{cccccccc}
\hline \multicolumn{2}{c}{ Temperature $\left({ }^{\circ} \mathbf{C}\right)$} & $\mathbf{3 0 0}$ & $\mathbf{4 0 0}$ & $\mathbf{5 0 0}$ & $\mathbf{6 0 0}$ & $\mathbf{7 0 0}$ & $\mathbf{8 0 0}$ \\
\hline Duration & Mineral oil & 2.54 & 2.36 & 2.83 & 2.57 & 2.84 & 2.37 \\
$(\mathrm{~min})$ & Vegetable oil & 3.64 & 3.34 & 3.40 & 3.15 & 2.82 & 2.56 \\
\hline
\end{tabular}

In order to simulate thermal faults of operating transformers approximately, the temperature and duration of simulated thermal faults are shown in Table 3.

Table 3. The temperature and duration of simulated thermal tests.

\begin{tabular}{|c|c|c|c|c|c|c|c|c|c|c|c|}
\hline \multirow{2}{*}{$\begin{array}{c}\text { Temperature } \\
\left({ }^{\circ} \mathrm{C}\right)\end{array}$} & \multicolumn{5}{|c|}{ T1 } & \multicolumn{5}{|c|}{$\mathrm{T} 2$} & \multirow{2}{*}{$\begin{array}{c}\text { T3 } \\
800\end{array}$} \\
\hline & 90 & 120 & 150 & 200 & 250 & 300 & 400 & 500 & 600 & 700 & \\
\hline Duration (h) & 168 & 168 & 168 & 2 & 1 & $1 / 2$ & $1 / 12$ & $1 / 12$ & $1 / 15$ & $1 / 20$ & $1 / 24$ \\
\hline
\end{tabular}




\subsubsection{Electrical Stress Simulation}

The experimental setup is shown in Figure 4. The step-up transformer is composed of a self-coupling voltage regulator and a testing transformer. The electrostatic voltmeter $\mathrm{V}$ is used to monitor voltage, resistor $\mathrm{R}$ is used to limit current. The $2000 \mathrm{pF}$ coupling capacitor capable of withstanding a voltage of $50 \mathrm{kV}$ is used to couple the pulse current generated by a partial discharge.

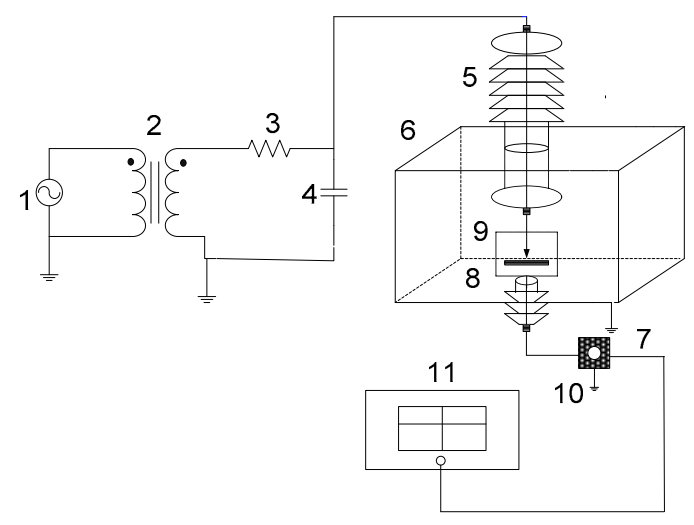

Figure 4. The sketch of electrical faults simulation setup. 1-AC power; 2-transformer; 3-protection resistance; 4-coupling capacitor; 5-high-voltage bushing; 6-tank; 7-ground wire; 8-ground bushing; 9-sample; 10-current sensor; and 11-oscilloscope.

To simulate breakdown in different insulation structures, six breakdown models with and without insulating paper are designed, as shown in Figure 5.

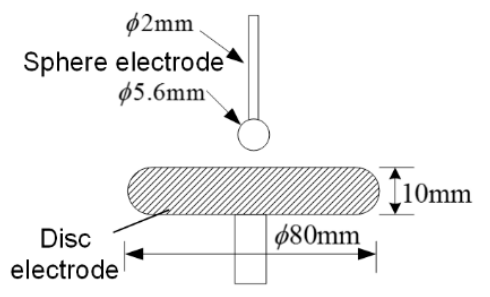

(a)

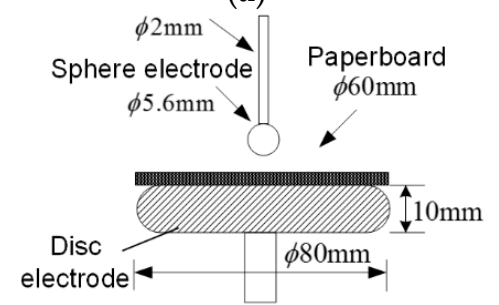

(d)

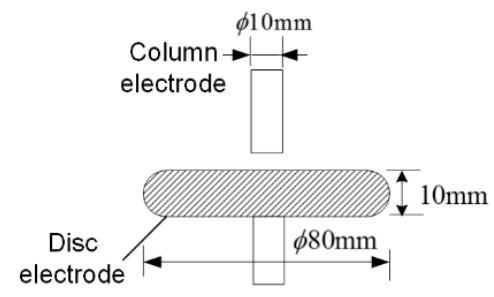

(b)

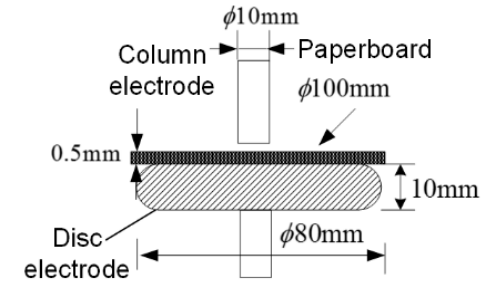

(e)

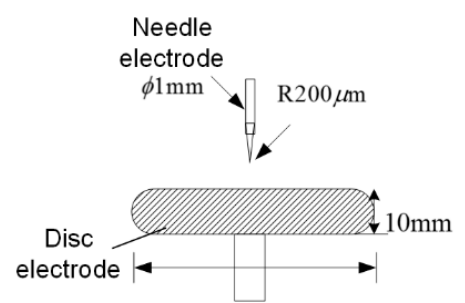

(c)

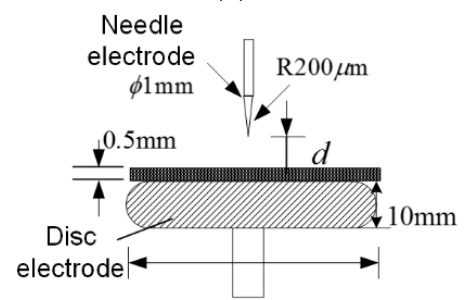

(f)

Figure 5. Sketch of breakdown models: (a) Sphere-disc electrode; (b) Column-disc electrode; (c) Needle-disc electrode; (d) Sphere-disc electrode (with paper); (e) Column-disc electrode (with paper); and (f) Needle-disc electrode (with paper).

To simulate a partial discharge in the transformers, four types of typical defect models-air gap discharge model, surface discharge model, floating discharge model, and corona in oil model-are used, as shown in Figure 6. 


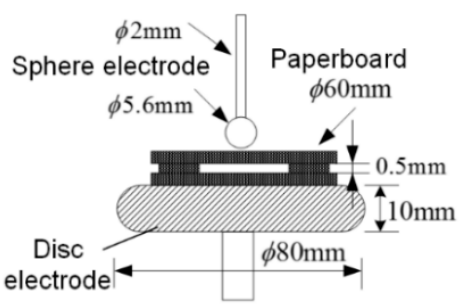

(a)

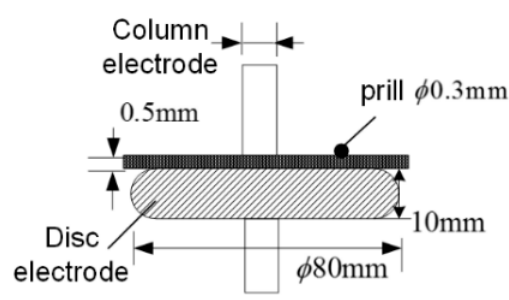

(c)

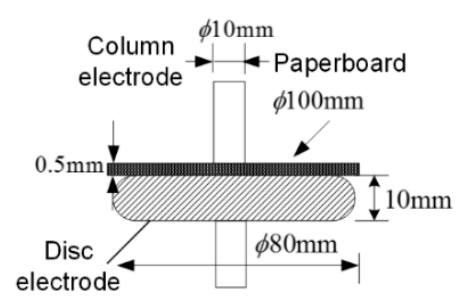

(b)

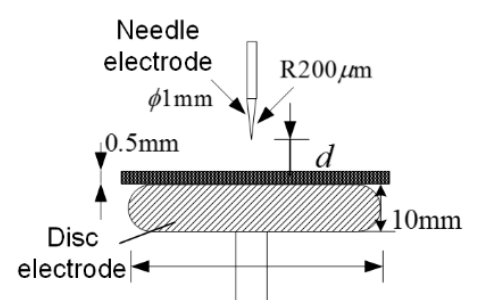

(d)

Figure 6. Sketch of typical insulation defect model: (a) Air gap discharge; (b) Surface discharge; (c) Floating discharge; and (d) Corona in oil.

\section{Dissolved Gas Analysis}

\subsection{DGA for Thermal Stress Simulation}

\subsubsection{DGA Results of Thermal Faults below $300^{\circ} \mathrm{C}$}

Figure 7 shows the relative percentages of fault gases, except $\mathrm{CO}$ and $\mathrm{CO}_{2}$, in mineral insulating oil, camellia, and FR3 insulating oil, which are overheated in the oven at $90{ }^{\circ} \mathrm{C}, 120{ }^{\circ} \mathrm{C}, 150{ }^{\circ} \mathrm{C}, 200^{\circ} \mathrm{C}$, and $250^{\circ} \mathrm{C} . \mathrm{C}_{2} \mathrm{H}_{2}$ is not obviously observed in all cases. FR3 and camellia oil generate a significant amount of $\mathrm{C}_{2} \mathrm{H}_{6}$, which does not largely exist in mineral oil. In camellia oil, $\mathrm{H}_{2}$ is generated in significant quantities. According to the percentage of fault gases, for FR3, the main dissolved gas is $\mathrm{C}_{2} \mathrm{H}_{6}$; for camellia oil, the main fault gases of are $\mathrm{C}_{2} \mathrm{H}_{6}$ and $\mathrm{H}_{2}$. This is different from mineral oil, whose main fault gases are $\mathrm{H}_{2}$ and $\mathrm{CH}_{4}$.

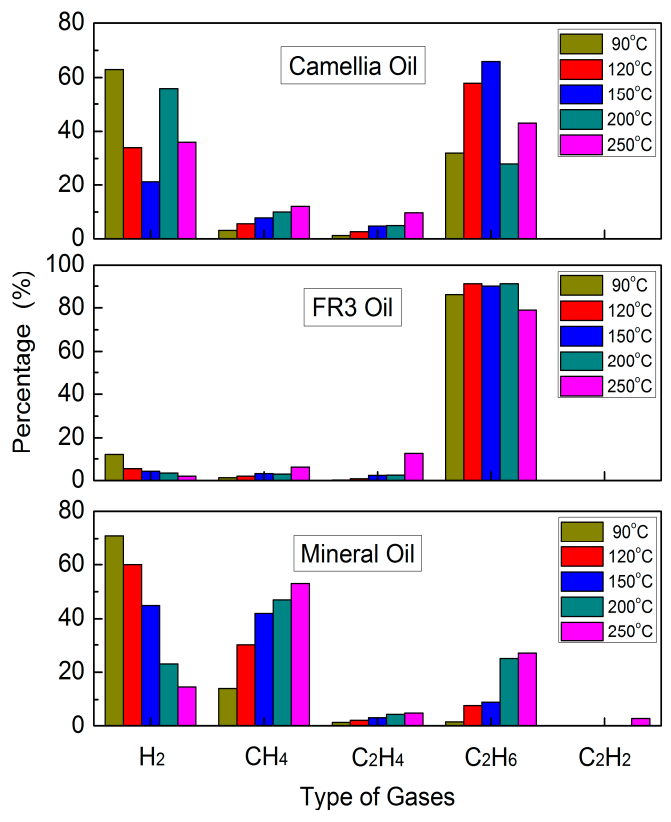

Figure 7. Relative percentages of fault gases in oil as a function of oven temperature (from $90{ }^{\circ} \mathrm{C}$ to $250{ }^{\circ} \mathrm{C}$ ). 
As shown in Table 4, compared to the case in oil insulation, the existence of insulating paper increases the amount of gases dissolved in oil. The $\mathrm{CO}_{2}$ content dissolved in FR3 oil-paper insulation are 2.5 times higher than that in FR3 oil insulation, and the ratio is six times of mineral oil. This is mainly due to the decomposition of cellulose forming hydrocarbons, alcohols, aldehydes, and acids, as well as the further decomposition of these molecules forming gas molecules, like $\mathrm{CO}$ and $\mathrm{CO}_{2}$.

Table 4. $\mathrm{CO}$ and $\mathrm{CO}_{2}$ content in oil under thermal faults below $300{ }^{\circ} \mathrm{C}$.

\begin{tabular}{|c|c|c|c|c|}
\hline Insulation Structure & Oil Type & Temperature $/{ }^{\circ} \mathrm{C}$ & $\mathrm{CO} / \mathrm{ppm}$ & $\mathrm{CO}_{2} / \mathrm{ppm}$ \\
\hline \multirow{6}{*}{ Oil } & \multirow[b]{2}{*}{ Camellia oil } & 90 & 49.3 & 1111.2 \\
\hline & & 200 & 68.8 & 1149.6 \\
\hline & \multirow[b]{2}{*}{ FR3 oil } & 90 & 24.2 & 918.9 \\
\hline & & 200 & 29.5 & 542.7 \\
\hline & \multirow{2}{*}{ Mineral oil } & 90 & 15.89 & 800.5 \\
\hline & & 200 & 85.4 & 781.4 \\
\hline \multirow{6}{*}{ Oil-Paper } & \multirow{2}{*}{ Camellia oil } & 90 & 65.3 & 1837.0 \\
\hline & & 200 & 1157.2 & $17,883.4$ \\
\hline & \multirow{2}{*}{ FR3 oil } & 90 & 29.2 & 1379.3 \\
\hline & & 200 & 468.5 & $11,568.4$ \\
\hline & \multirow{2}{*}{ Mineral oil } & 90 & 190.3 & 2638.6 \\
\hline & & 200 & 327.9 & 8192.8 \\
\hline
\end{tabular}

Figure 8 shows the relative percentages of fault gases in oil-paper insulation except $\mathrm{CO}$ and $\mathrm{CO}_{2}$ below $300{ }^{\circ} \mathrm{C}$. In mineral oil, the content of $\mathrm{H}_{2}$ and $\mathrm{CH}_{4}$ is the highest. In FR3 oil, the content of $\mathrm{C}_{2} \mathrm{H}_{6}$ is the highest. In camellia oil, the content of $\mathrm{C}_{2} \mathrm{H}_{6}$ is slightly higher than other types of gases, except $\mathrm{H}_{2}$.

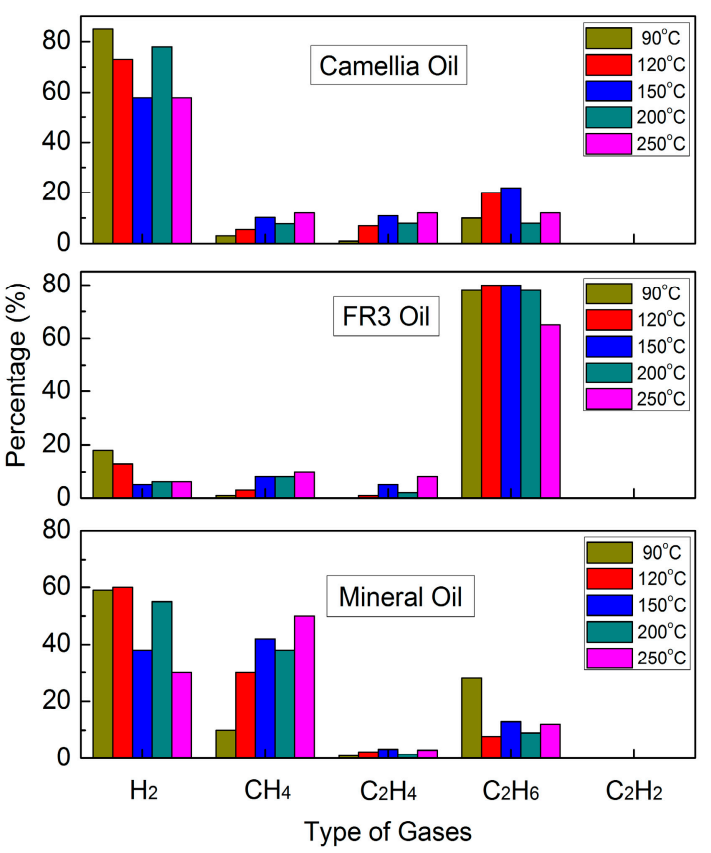

Figure 8. Relative percentages of fault gases in oil-paper insulation as a function of oven temperature (from $90{ }^{\circ} \mathrm{C}$ to $250{ }^{\circ} \mathrm{C}$ ).

\subsubsection{DGA Results of Thermal Faults above $300^{\circ} \mathrm{C}$}

Figure 9 shows the relative percentages of fault gases, except $\mathrm{CO}$ and $\mathrm{CO}_{2}$, in mineral insulating oil, FR3, and camellia insulating oil which are overheated in the muffle furnace at $300{ }^{\circ} \mathrm{C}, 400{ }^{\circ} \mathrm{C}$, 
$500{ }^{\circ} \mathrm{C}, 600{ }^{\circ} \mathrm{C}, 700{ }^{\circ} \mathrm{C}$, and $800{ }^{\circ} \mathrm{C} . \mathrm{C}_{2} \mathrm{H}_{2}$ is also not obviously observed in all cases. In mineral oil, $\mathrm{CH}_{4}$ is a key indicator of overheated oil, and $\mathrm{C}_{2} \mathrm{H}_{4}$ is a secondary indicator of overheated oil. However, $\mathrm{CH}_{4}$ and $\mathrm{C}_{2} \mathrm{H}_{4}$ do not largely exist in FR3 and camellia oil. In contrast, FR3 and camellia oil generate a significant amount of $\mathrm{C}_{2} \mathrm{H}_{6}$, which does not largely exist in mineral oil. In camellia oil, $\mathrm{H}_{2}$ is generated in significant quantities. According to the percentage of fault gases, the main dissolved gas for FR3 oil is $\mathrm{C}_{2} \mathrm{H}_{6}$, and the main dissolved gases in camellia oil are $\mathrm{C}_{2} \mathrm{H}_{6}$ and $\mathrm{H}_{2}$, while that for mineral oil is $\mathrm{CH}_{4}$.

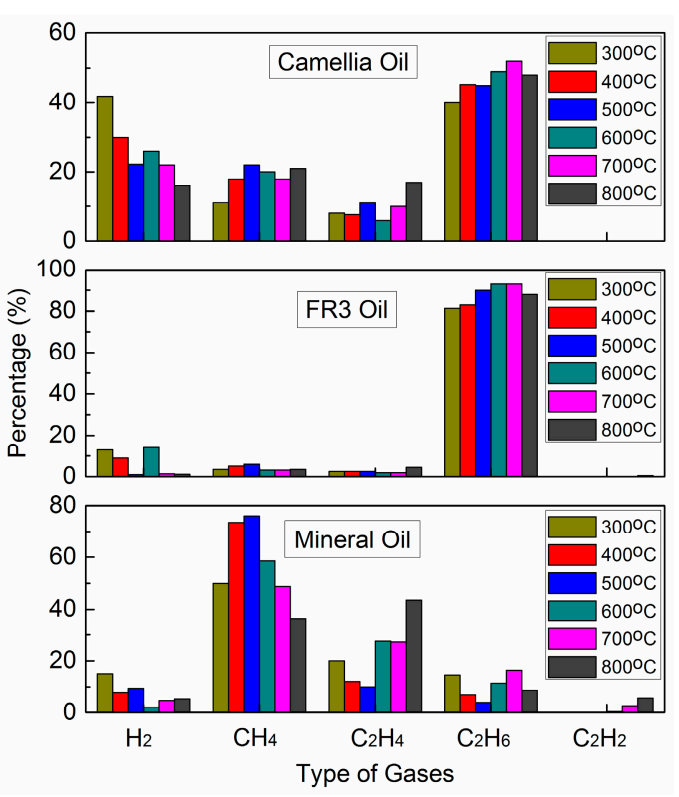

Figure 9. Relative percentages of fault gases in oil as a function of oven temperature (from $300{ }^{\circ} \mathrm{C}$ to $\left.800{ }^{\circ} \mathrm{C}\right)$.

As with the result obtained in the case under thermal faults below $300{ }^{\circ} \mathrm{C}$, the existence of insulating paper also increases the amount of $\mathrm{CO}$ and $\mathrm{CO}_{2}$ significantly under thermal faults above $300^{\circ} \mathrm{C}$, as shown in Table 5 .

Table 5. $\mathrm{CO}$ and $\mathrm{CO}_{2}$ content in oil under thermal faults above $300{ }^{\circ} \mathrm{C}$.

\begin{tabular}{|c|c|c|c|c|}
\hline Insulation Structure & Oil Type & Temperature $/{ }^{\circ} \mathrm{C}$ & $\mathrm{CO} / \mathrm{ppm}$ & $\mathrm{CO}_{2} / \mathrm{ppm}$ \\
\hline \multirow{6}{*}{ Oil } & \multirow{2}{*}{ Camellia oil } & 400 & 74.64 & 2664.4 \\
\hline & & 700 & 1854.3 & $10,517.3$ \\
\hline & \multirow[b]{2}{*}{ FR3 oil } & 400 & 434.6 & 2430.7 \\
\hline & & 700 & 1553.3 & 8945.1 \\
\hline & \multirow{2}{*}{ Mineral oil } & 400 & 250.8 & 2038.8 \\
\hline & & 700 & 1797.9 & 9845.1 \\
\hline \multirow{6}{*}{ Oil-Paper } & \multirow{2}{*}{ Camellia oil } & 400 & 160.2 & 3628.4 \\
\hline & & 700 & 1792.4 & $12,481.1$ \\
\hline & \multirow{2}{*}{ FR3 oil } & 400 & 171.5 & 3536.2 \\
\hline & & 700 & 1487.3 & $21,527.1$ \\
\hline & \multirow{2}{*}{ Mineral oil } & 400 & 190.3 & 3160.1 \\
\hline & & 700 & 327.9 & $43,957.3$ \\
\hline
\end{tabular}

Figure 10 shows the relative percentages of fault gases in oil-paper insulation, except $\mathrm{CO}$ and $\mathrm{CO}_{2}$, above $300{ }^{\circ} \mathrm{C}$. In mineral oil, the content of $\mathrm{CH}_{4}$ is highest; in FR3 oil, the content of $\mathrm{C}_{2} \mathrm{H}_{6}$ is highest; in camellia oil, the content of $\mathrm{C}_{2} \mathrm{H}_{6}$ is higher than other types of gases, followed by $\mathrm{H}_{2}$. According to the 
percentage of fault gases, for FR3, the main dissolved gas is $\mathrm{C}_{2} \mathrm{H}_{6}$; for camellia oil, the main fault gases are $\mathrm{C}_{2} \mathrm{H}_{6}$ and $\mathrm{H}_{2}$. This is different from mineral oil, whose main dissolved gases are $\mathrm{CH}_{4}$ and $\mathrm{C}_{2} \mathrm{H}_{6}$.

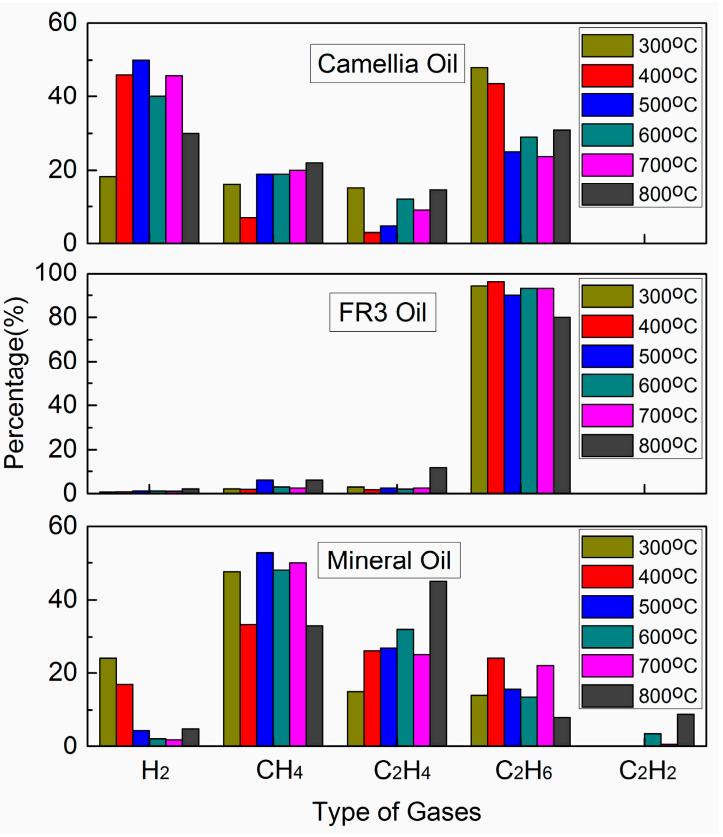

Figure 10. Relative percentages of fault gases in oil-paper insulation as a function of oven temperature (from $300{ }^{\circ} \mathrm{C}$ to $800{ }^{\circ} \mathrm{C}$ ).

\subsection{DGA for Electrical Stress Simulation}

Figure 11 shows the relative percentages of fault gases, except $\mathrm{CO}$ and $\mathrm{CO}_{2}$, under electrical breakdown. In all cases, a significant amount of $\mathrm{H}_{2}$ and $\mathrm{C}_{2} \mathrm{H}_{2}$ are generated, it indicates that for mineral oil, FR3 oil, and camellia oil, the main fault gases of a breakdown fault are the same.

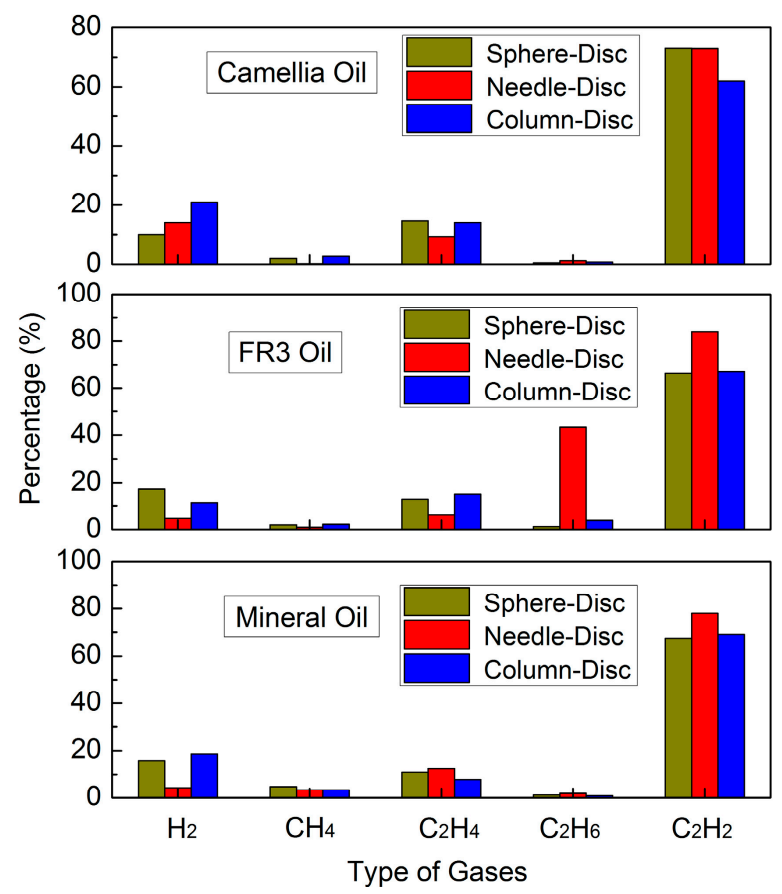

Figure 11. Relative percentages of fault gases in oil under breakdown. 
As shown in Table 6, compared to the case in pure oil, the content of $\mathrm{CO}$ and $\mathrm{CO}_{2}$ in oil-paper insulation under breakdown is higher. This is mainly because under electrical stress, the decomposition of $\mathrm{C}-\mathrm{O}$ bonds in the cellulose forms $\mathrm{O}_{2}$, the reactions of $\mathrm{O}_{2}$ and $\mathrm{C}$ in cellulose produce $\mathrm{CO}$ and $\mathrm{CO}_{2}$.

Table 6. $\mathrm{CO}$ and $\mathrm{CO}_{2}$ content (in ppm) in oil under needle-disc breakdown.

\begin{tabular}{ccccc}
\hline Insulation Structure & Gas Type & Camellia Oil & FR3 Oil & Mineral Oil \\
\hline \multirow{2}{*}{ Oil } & $\mathrm{CO}$ & 15.52 & 9.11 & 15.52 \\
& $\mathrm{CO}_{2}$ & 1259.49 & 690.16 & 1295.49 \\
\hline \multirow{2}{*}{ Oil-Paper } & $\mathrm{CO}$ & 442.31 & 563.85 & 86.88 \\
& $\mathrm{CO}_{2}$ & 1704.2 & 1012.31 & 912.74 \\
\hline
\end{tabular}

Figure 12 shows the relative percentages of fault gases except $\mathrm{CO}$ and $\mathrm{CO}_{2}$ under electrical breakdown. As the case in the oil insulation, a significant amount of $\mathrm{H}_{2}$ and $\mathrm{C}_{2} \mathrm{H}_{2}$ are dissolved in all samples. It shows that $\mathrm{C}_{2} \mathrm{H}_{2}$ is the main dissolved gas of electrical breakdown for mineral oil, FR3 oil, and camellia oil.

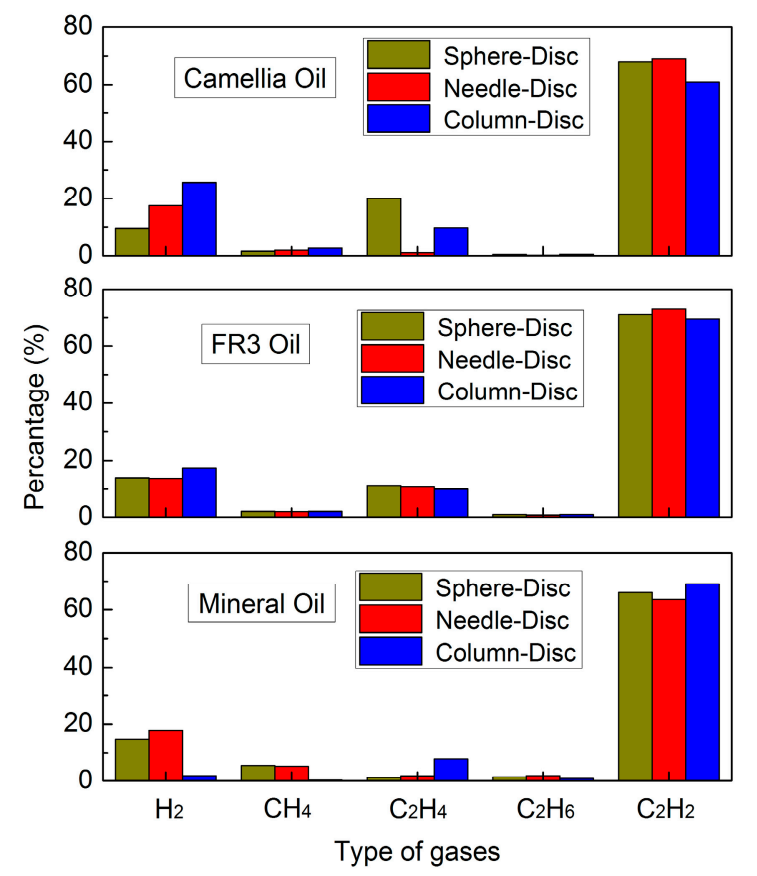

Figure 12. Relative percentages of fault gases in oil-paper under breakdown.

Table 7 shows fault gas contents (in ppm) under partial discharge; the contents are mainly dependent on discharge energy, and it is hard to distinguish a partial discharge pattern through DGA.

Table 7. Fault gas contents (in ppm) in oil under partial discharge.

\begin{tabular}{ccccc}
\hline Model & Gas Type & Camellia Oil & FR3 Oil & Mineral Oil \\
\hline \multirow{4}{*}{ Air gap } & $\mathrm{H}_{2}$ & 6.2 & 25.64 & 13.54 \\
& $\mathrm{THGC}^{*}$ & 7.7 & 23.66 & 3.39 \\
& $\mathrm{CO}$ & 37.4 & 22.47 & 4.39 \\
& $\mathrm{CO}_{2}$ & 357.63 & 349.63 & 202.5 \\
\hline
\end{tabular}

* THGC is the total hydrocarbon gas contents. 
Figure 13 shows the relative percentages of fault gases, except $\mathrm{CO}$ and $\mathrm{CO}_{2}$, under partial discharge. In mineral oil, the content of $\mathrm{H}_{2}$ is highest, followed by $\mathrm{CH}_{4}$; in $\mathrm{FR} 3$ oil, the content of $\mathrm{H}_{2}$ is highest, followed by $\mathrm{C}_{2} \mathrm{H}_{6}$; in camellia oil, the content of $\mathrm{H}_{2}$ is highest, and followed by $\mathrm{CH}_{4}$ and $\mathrm{C}_{2} \mathrm{H}_{6} . \mathrm{C}_{2} \mathrm{H}_{2}$ does not largely exist in all samples, which shows that $\mathrm{C}_{2} \mathrm{H}_{2}$ is only the main dissolved gas of high-energy discharge.

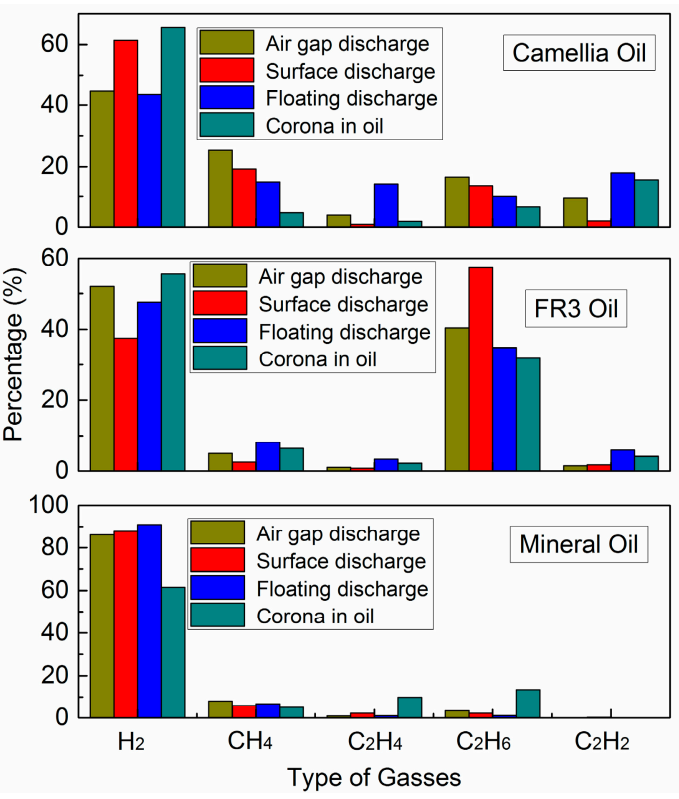

Figure 13. Relative percentages of fault gases in oil under partial discharge.

\section{Diagnostic Results Based on DGA}

\subsection{Three-Ratio Method}

The three-ratio method was used to analyze the experiment data, the consistencies of the diagnosis results and actual fault types are shown in Table 8.

Table 8. Consistencies of diagnosis results and simulated fault types.

\begin{tabular}{clll}
\hline Temperature $/{ }^{\circ} \mathbf{C}$ & Mineral Oil & FR3 & Camellia Oil \\
\hline 90 & Conformity & Inconformity & Inconformity \\
120 & Conformity & Inconformity & Inconformity \\
150 & Conformity & Conformity & Inconformity \\
200 & Conformity & Conformity & Inconformity \\
250 & Conformity & Inconformity & Conformity \\
300 & Conformity & Inconformity & Inconformity \\
400 & Conformity & Inconformity & Inconformity \\
500 & Conformity & Inconformity & Inconformity \\
600 & Conformity & Inconformity & Inconformity \\
700 & Conformity & Inconformity & Inconformity \\
800 & Conformity & Inconformity & Inconformity \\
\hline
\end{tabular}

The three-ratio method can correctly diagnose thermal faults in mineral insulating oil-filled transformers in all simulated situations; however, it makes incorrect conclusions when it is applied to vegetable insulating oils in most cases. This result is attributed to the difference in the molecular chemical structure between mineral insulating oil and vegetable insulating oil. The traditional three-ratio method for mineral insulating oil fill-transformers need to be reconsidered when they are applied to vegetable insulating oil filled-transformer. 
When the three-ratio method was applied to analyze the data of simulated electrical faults in mineral oil, the diagnosis results are correct in all cases. However, when it is applied to analyze data in FR3 oil and camellia oil, it only diagnoses breakdown faults correctly; the diagnosis results are not consistent with simulated fault types under partial discharge, as shown in Table 9.

Table 9. Consistencies of diagnosis results and simulated fault types.

\begin{tabular}{clll}
\hline Model & Mineral Oil & FR3 & Camellia Oil \\
\hline Sphere-disc (oil) & Conformity & Conformity & Conformity \\
Needle-disc (oil) & Conformity & Conformity & Conformity \\
Column-disc (oil) & Conformity & Conformity & Conformity \\
Sphere-disc (oil-paper) & Conformity & Conformity & Conformity \\
Needle-disc (oil-paper) & Conformity & Conformity & Conformity \\
Column-disc (oil-paper) & Conformity & Conformity & Conformity \\
Air gap & Conformity & Inconformity & Inconformity \\
Surface discharge & Conformity & Inconformity & Inconformity \\
Floating discharge & Conformity & Inconformity & Inconformity \\
Corona in oil & Conformity & Inconformity & Inconformity \\
\hline
\end{tabular}

\subsection{Graph Representaion Method}

Figure 14 shows diagnosis results of simulated thermal faults using the graph representation method in IEC 60599. In terms of results of mineral oil, the graph representation method diagnoses the majority of faults correctly. However, for FR3 oil and camellia oil, the majority of thermal faults are identified as the normal state or partial discharge. It shows that the graph representation method is no longer suitable for diagnosis of thermal faults in vegetable insulating oil.

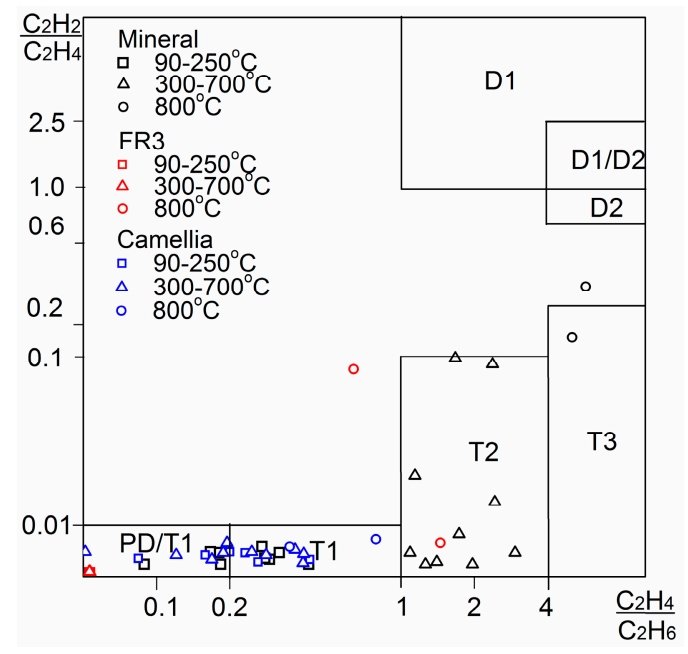

(a)

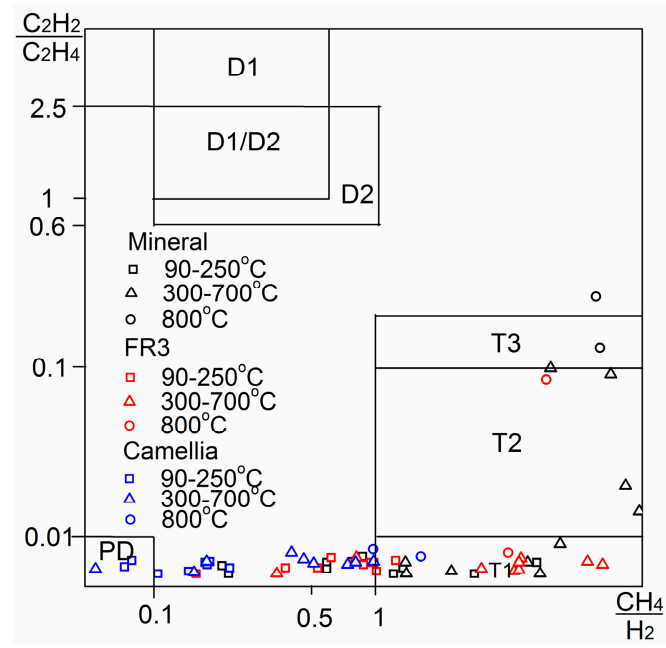

(b)

Figure 14. Diagnostic results of simulated thermal faults using graph representation method (data in the figure are expressed as a function of oven temperature): (a) According to the ratio of $\mathrm{C}_{2} \mathrm{H}_{2} / \mathrm{C}_{2} \mathrm{H}_{4}$ and $\mathrm{C}_{2} \mathrm{H}_{4} / \mathrm{C}_{2} \mathrm{H}_{6} ;(\mathbf{b})$ According to the ratio of $\mathrm{C}_{2} \mathrm{H}_{2} / \mathrm{C}_{2} \mathrm{H}_{4}$ and $\mathrm{CH}_{4} / \mathrm{H}_{2}$.

Figure 15 shows diagnosis results of simulated electrical faults using the graph representation method in IEC 60599. For mineral oil, FR3 oil, and camellia oil, the graph representation method correctly diagnoses the majority of breakdown faults. In terms of the diagnosis results of partial discharge faults, most ratio points of mineral oil fall into the correct fault zone; however, for FR3 and camellia oil, the majority of partial discharge faults are not correctly diagnosed. 


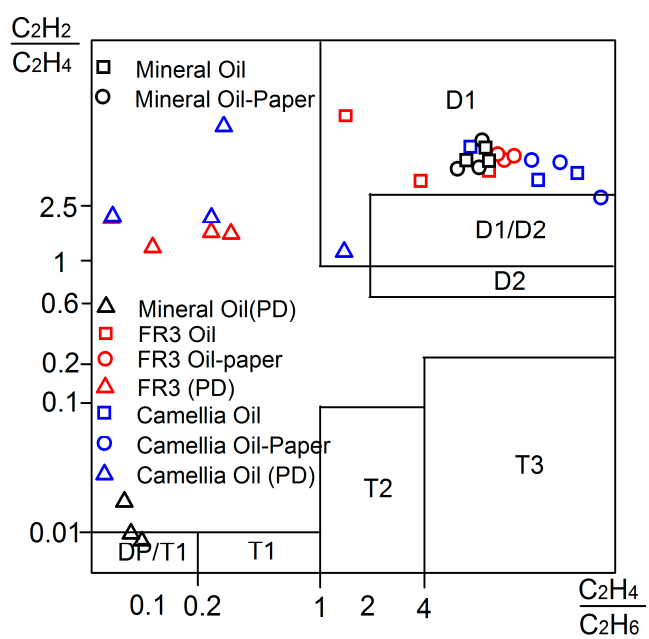

(a)

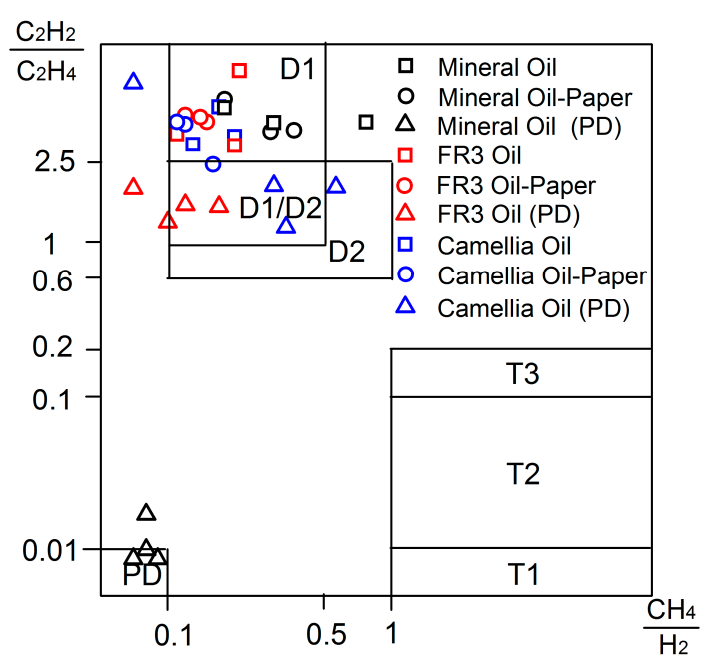

(b)

Figure 15. Diagnostic results of simulated electrical faults using graph representation method: (a) According to the ratio of $\mathrm{C}_{2} \mathrm{H}_{2} / \mathrm{C}_{2} \mathrm{H}_{4}$ and $\mathrm{C}_{2} \mathrm{H}_{4} / \mathrm{C}_{2} \mathrm{H}_{6}$; (b) According to the ratio of $\mathrm{C}_{2} \mathrm{H}_{2} / \mathrm{C}_{2} \mathrm{H}_{4}$ and $\mathrm{CH}_{4} / \mathrm{H}_{2}$.

\subsection{Duval Triangle and Pentagon Method}

Figure 16 shows the diagnosis results of thermal faults using Duval Triangle 1 in IEC 60599. In terms of mineral oil, Duval Triangle 1 correctly diagnoses all thermal faults. For FR3, part of the simulated faults carried out at $90^{\circ} \mathrm{C}-250{ }^{\circ} \mathrm{C}$ are placed incorrectly into the $\mathrm{T} 2\left(300{ }^{\circ} \mathrm{C}-700{ }^{\circ} \mathrm{C}\right)$ region. For camellia oil, several simulated faults carried out at $90^{\circ} \mathrm{C}-250^{\circ} \mathrm{C}$ are also incorrectly allocated to the $\mathrm{T} 2$ region.

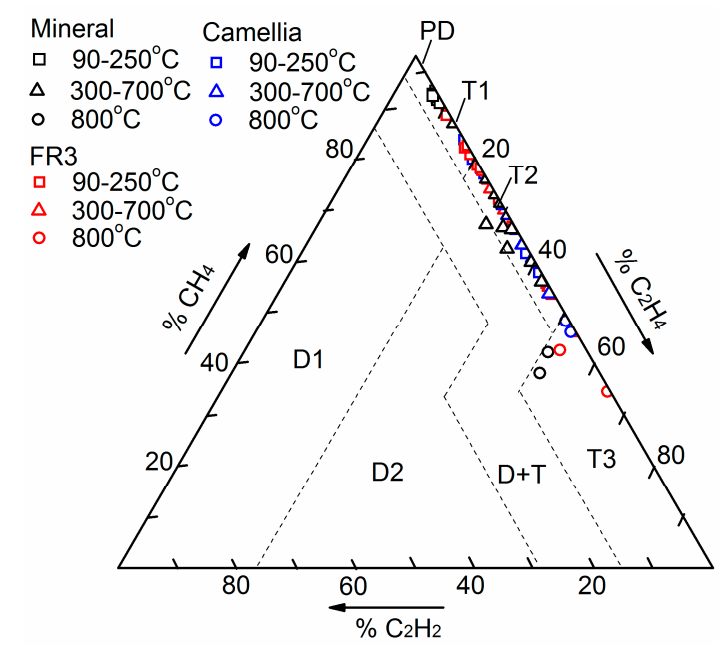

Figure 16. Diagnostic results of simulated thermal faults using Duval Triangle 1 (data in the figure are expressed as a function of oven temperature).

Figure 17 shows the diagnosis results of electrical faults using Duval Triangle 1. Unlike the case in simulated thermal faults, for all oils, the use of the Duval Triangle method diagnose nearly all electrical breakdown cases correctly. 


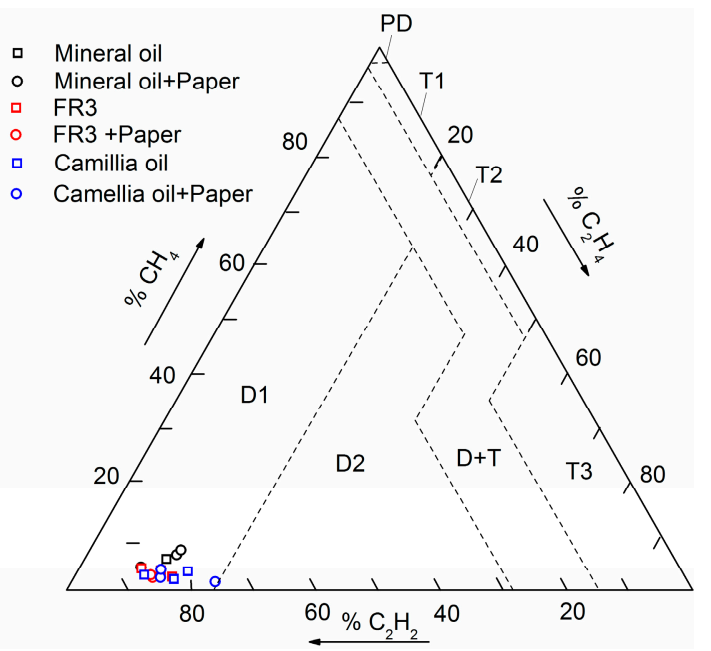

Figure 17. Diagnostic results of simulated electrical faults using Duval Triangle 1.

Figure 18 shows the diagnosis results of thermal faults using the Duval Pentagon proposed by Duval in 2014 [6]. The Duval Pentagon was designed to diagnose the fault of mineral oil. Therefore, for mineral oil, the Duval Pentagon correctly diagnoses almost all thermal faults. However, for FR3 and camellia oil, all of the thermal fault data are placed incorrectly into the stray gassing region. The diagnostic results gathered in one region mainly because percentages of $\mathrm{C}_{2} \mathrm{H}_{6}$ produced by vegetable oils are much higher than the mineral oil.

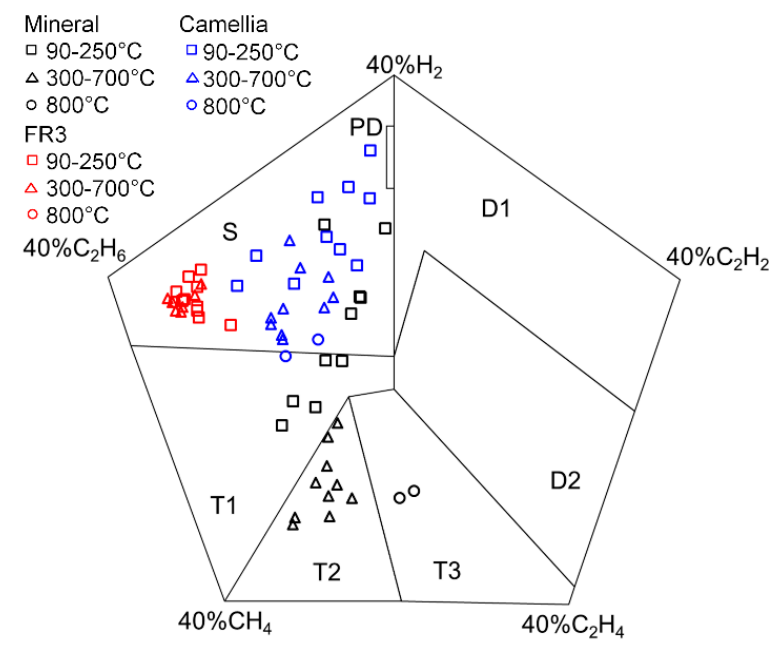

Figure 18. Diagnostic results of simulated thermal faults using the Duval Pentagon (data in the figure are expressed as a function of oven temperature).

Figure 19 shows the diagnosis results of thermal faults using the Duval Pentagon. For all of the three types of oil, the use of the Duval Pentagon method diagnose nearly all electrical breakdown faults correctly.

Furthermore, Duval has proposed Duval Triangle 3, which is applied to diagnose the thermal and electrical faults of four types of natural and synthetic ester, including FR3 [19]. Duval Triangle 3 is obtained by adjusting the zone boundaries of Duval Triangle 1. Figure 20 shows the diagnosis result of electrical and thermal faults of FR3 oil using Duval Triangle 3. For FR3 oil, the modification of the Duval Triangle results in more correct diagnostic results. The fault gases data of electrical faults are all placed in the region D1. The fault data of thermal faults at $300{ }^{\circ} \mathrm{C}, 300^{\circ} \mathrm{C}$ to $700{ }^{\circ} \mathrm{C}$, and above 
$700{ }^{\circ} \mathrm{C}$ are placed more correctly than other diagnostic methods, and only a few of them fall in the wrong region.

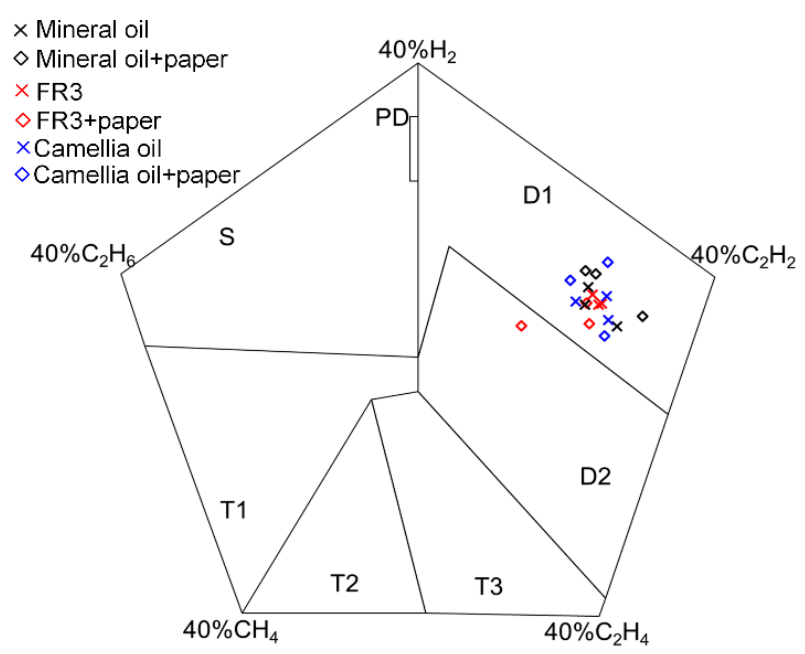

Figure 19. Diagnostic results of simulated electrical faults using the Duval Pentagon.

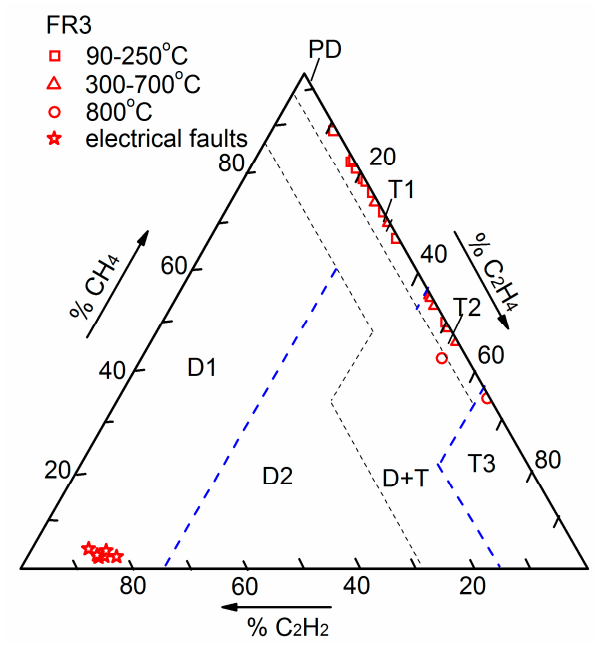

Figure 20. Diagnostic results of thermal and electrical faults of FR3 oil using Duval Triangle 3 (data in the figure are expressed as a function of oven temperature).

As Duval illustrated in [19], non-mineral oil with different chemical structures may result in different gas patterns and zone boundaries. Thus, for camellia oil, since it has different chemical compositions with FR3, the zone boundaries which are suitable for FR3 are not applicable to camellia oil. Figure 21 shows the new boundaries divided according to different types of fault data of camellia oil and the diagnosis results using this modified Duval Triangle 3. As shown in the figure, only two fault data which should be placed in T1 region fall in the region of T2, and also only two data which should be placed in $\mathrm{T} 2$ region fall in the T1 region. Other fault data are all placed in the correct regions. It is obvious that the adjustment of zone boundaries of Duval Triangle 3 makes the diagnostic result of thermal and electrical faults of camellia oil more correctly. Of course, this modification needs to be verified by more fault data through further research. 


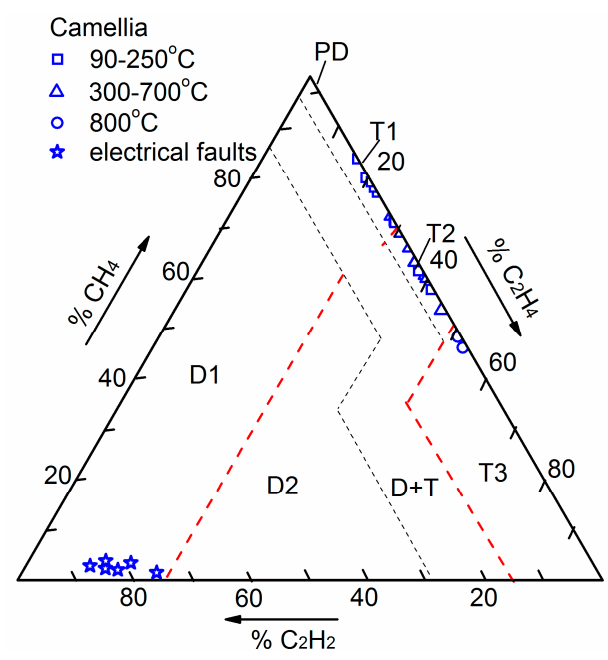

Figure 21. Diagnostic results of thermal and electrical faults of camellia oil based on the modified Duval Triangle 3 (data in the figure are expressed as a function of oven temperature).

\subsection{Law of Key Gases Dissolved in Oils}

A thermal fault is caused by effective thermal stress with a middle level of energy density. It should be noted that there is some difference between simulation faults and practical operation faults, but the basic mechanisms are the same. According to the experimental results, it could be identified that the main fault gases of overheated oil in mineral oil, FR3, and camellia oil are $\mathrm{CH}_{4}$ and $\mathrm{C}_{2} \mathrm{H}_{4}, \mathrm{C}_{2} \mathrm{H}_{6}, \mathrm{H}_{2}$ and $\mathrm{C}_{2} \mathrm{H}_{6}$, respectively.

The test results demonstrate that the percentage of main fault gases increase regularly with the increase of temperature. In mineral oil, the percentage of $\mathrm{CH}_{4}$ and $\mathrm{C}_{2} \mathrm{H}_{4}$ increase with the increasing temperature. This was in good agreement with the results of the practical situation in mineral oil-filled transformer. In the overheating process of $F R 3$, the percentage of $\mathrm{C}_{2} \mathrm{H}_{6}$ also increases as the temperature increases. In camellia oil, the percentage of $\mathrm{H}_{2}$ increases while the percentage of $\mathrm{C}_{2} \mathrm{H}_{6}$ fluctuates with the increase of temperature. The level of thermal faults cannot be determined according to the percentage of $\mathrm{C}_{2} \mathrm{H}_{6}$ in camellia oil.

Under electrical breakdown, $\mathrm{C}_{2} \mathrm{H}_{2}$ is the key indicator for mineral insulating oil, FR3 and camellia insulating oil. Due to this consistency, diagnostic methods in IEC 60599 can correctly diagnose electrical breakdown in mineral insulating oil and vegetable insulating oils.

\section{Gas Formation Mechanisms under Thermal Stress}

A chemical reaction is a process that generates new products through the chain scission mechanism. Vegetable insulating oil mainly consists of triglycerides, which are actually generated from the esterification reaction. The decomposition of vegetable insulating oil, from the microscopic point of view, involves the breaking of chemical bonds, dehydration, and formation of small-molecular gas.

There are hundreds of triglycerides, which are formed by ester groups and various types of fatty acid groups, inside vegetable insulating oil. Therefore, due to the various structures and the multiplicity of possible reactions of mixed triglycerides, mechanisms of the gas generation of vegetable insulating oil are complex. Table 10 shows the composition and the content of various types of fatty acids in soybean oil (the raw material of FR3 oil) and camellia oil. It is obvious that the major differences of the fatty acids content between FR3 oil and camellia oil are the content of mono-unsaturated fatty acids and double-unsaturated fatty acids. In vegetable oil, mono-unsaturated fatty acids are mainly composed of oleic acid while double-unsaturated fatty acids are mainly composed of linoleic acid. Thus, oleic-type triglyceride and linoleic-type triglyceride are chosen to interpret the different characteristics of gas generation between FR3 oil and camellia oil. 
Table 10. Fatty acid content of soybean oil and camellia oil (\%).

\begin{tabular}{ccccc}
\hline \multirow{2}{*}{ Vegetable Oil } & \multirow{2}{*}{ Saturated Fatty Acid } & \multicolumn{3}{c}{ Unsaturated Fatty Acids } \\
\cline { 3 - 5 } & & Mono-Unsaturated & Double-Unsaturated & Poly-Unsaturated \\
\hline Soybean Oil & 14.2 & 22.5 & 51.0 & 12.3 \\
Camellia Oil & 10.2 & 78.3 & 7.0 & 4.5 \\
\hline
\end{tabular}

According to several studies of pyrolysis of unsaturated triglyceride [26-29], the principal decomposition reactions of triglyceride are obtained. However there are multichannel reactions; the decomposition pathway of triglycerides and the intermediate product of the reactions could not be explicitly described through current experiments. Thus, unimolecular pyrolysis simulations are studied, and the standard enthalpies of reaction are calculated using M06-2x method with empirical dispersion in conjunction with the 6-31G $(\mathrm{d}, \mathrm{p})$ basis sets. As a result, the decomposition pathways of oleic-type triglyceride and linoleic-type triglyceride and the standard reaction enthalpies of each reactions are shown in Figures 22 and 23.

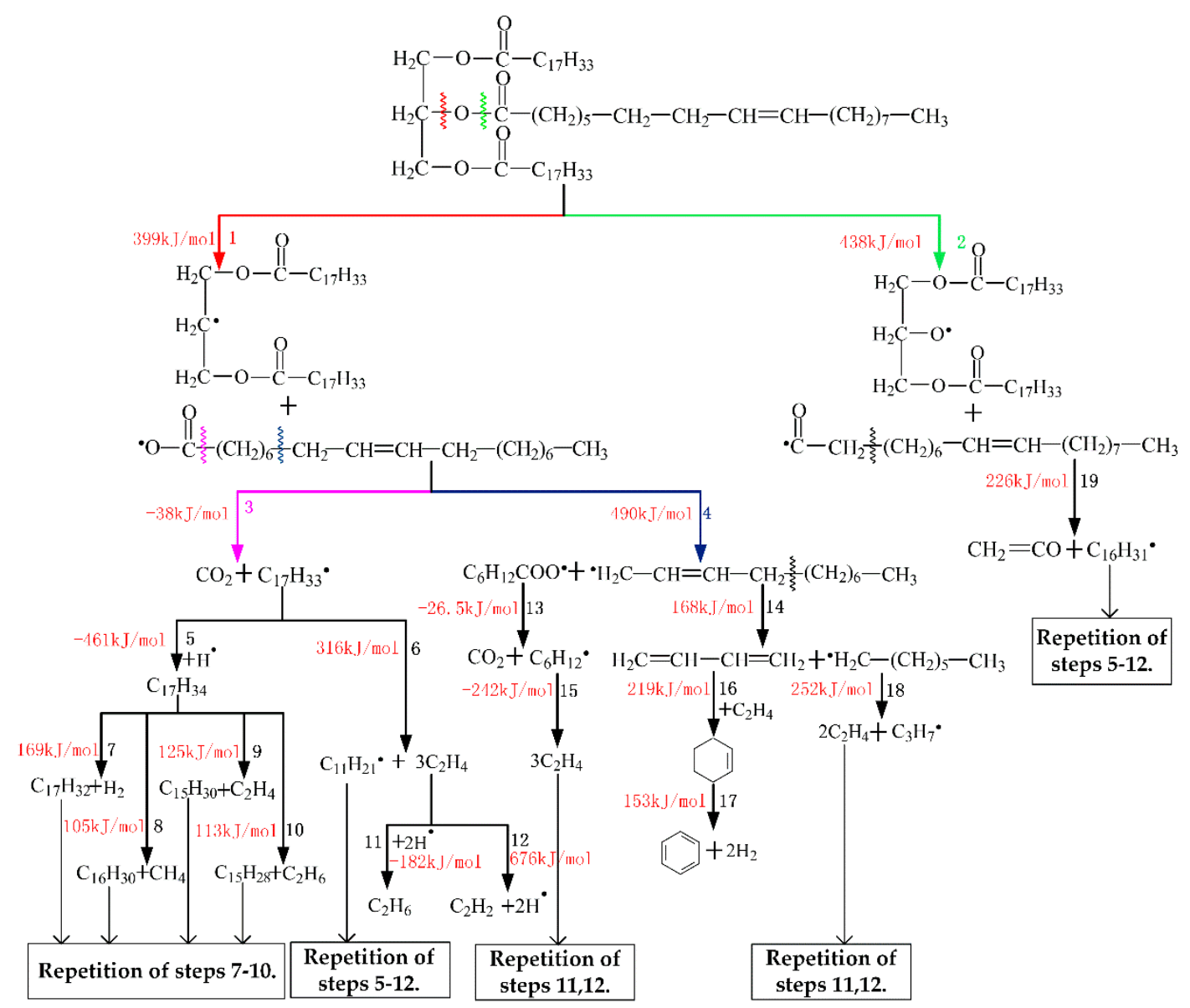

Figure 22. The principal decomposition pathways of oleic-type triglyceride and their standard enthalpies of reactions calculated using M06-2x method.

As it is shown in Figure 22, the $\mathrm{C}_{17} \mathrm{H}_{33} \mathrm{COO}$. radical and $\mathrm{C}_{17} \mathrm{H}_{33} \mathrm{CO}$. radical are generated from oleic-type molecule decomposition at first. According to the calculation result of the standard reaction enthalpies $(\Delta E)$ of these two reactions, the calculated $\Delta E$ value of the cleavage of $C-O$ bond is $399 \mathrm{~kJ} / \mathrm{mol}$, while that of the $\mathrm{O}-\mathrm{C}(=\mathrm{O})$ bond is $438 \mathrm{~kJ} / \mathrm{mol}$. This means that it has a higher possibility to break the $\mathrm{C}-\mathrm{O}$ bond than $\mathrm{O}-\mathrm{C}(=\mathrm{O})$ bond; therefore, the formation of fatty acid radicals will be the 
initial decomposition intermediate products. This is consistent with the result obtained in [27] using the GC-MS analysis method.

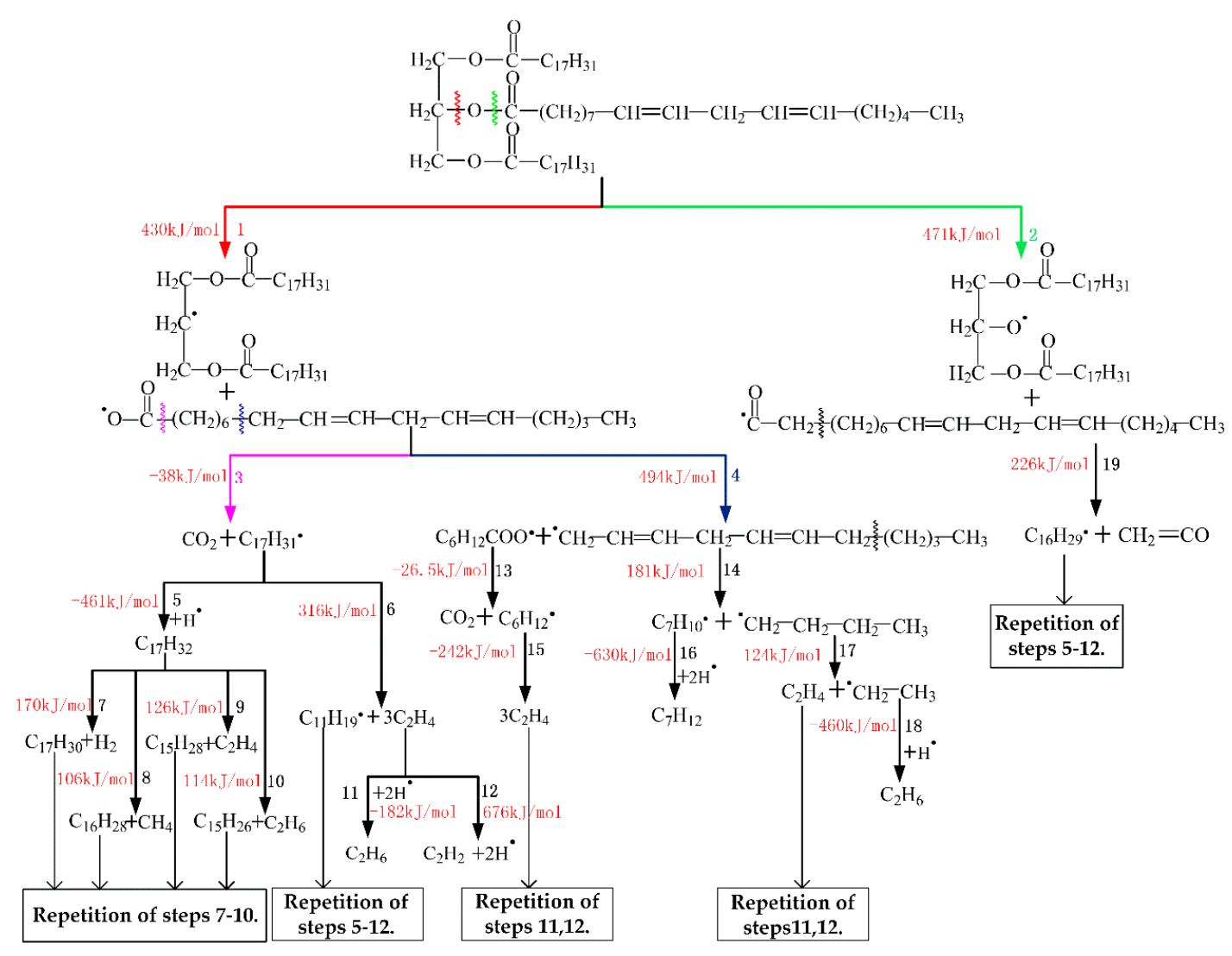

Figure 23. The principal decomposition pathways of linoleic-type triglyceride and their standard enthalpies of reactions calculated using M06-2x method.

Then $\mathrm{C}_{17} \mathrm{H}_{33} \mathrm{COO}$. radical continues to decompose in several pathways and the two most possible pathways (pathway 3 and 4 ) are displayed in the figure.

Pathway 3 leads to the formation of $\mathrm{C}_{17} \mathrm{H}_{33}$. radicals by decarboxylation, which is the reason why $\mathrm{CO}_{2}$ in vegetable insulating oil is higher than that in mineral insulating oil. Then, $\mathrm{C}_{17} \mathrm{H}_{33}$. radicals combine with $\mathrm{H}$. radicals and generate alkenes $\mathrm{C}_{17} \mathrm{H}_{34}$ (pathway 5) or decompose directly and generate $\mathrm{C}_{2} \mathrm{H}_{4}$ (pathway 6). The intermediate product $\mathrm{C}_{2} \mathrm{H}_{4}$ combines with $\mathrm{H}$. radicals and generates $\mathrm{C}_{2} \mathrm{H}_{6}$ (pathway 11), which is the main reason that $\mathrm{C}_{2} \mathrm{H}_{6}$ in vegetable insulating oil is higher than that in mineral insulating oil. The $\mathrm{C}_{2} \mathrm{H}_{4}$ can also decompose to $\mathrm{C}_{2} \mathrm{H}_{2}$ through the dehydrogenation reaction (pathway 12), however the calculated $\Delta E$ value of the dehydrogenation reaction is very high and it is not easy to reach unless the energy reaches a high level.

Pathway 4 leads to the formation of $\mathrm{C}_{6} \mathrm{H}_{12} \mathrm{COO}$. radicals and $\mathrm{C}_{11} \mathrm{H}_{21}$. radicals because the unsaturated sites enhance cleavage at the position which is marked in the figure. Then, the $\mathrm{C}_{6} \mathrm{H}_{12} \mathrm{COO}$. radical decomposes to $\mathrm{CO}_{2}$ (pathway 13) and $\mathrm{C}_{2} \mathrm{H}_{4}$ (pathway 15). The $\mathrm{C}_{11} \mathrm{H}_{21}$. radical continues to decompose to $\mathrm{CH}_{2}=\mathrm{CH}-\mathrm{CH}=\mathrm{CH}_{2}$ and $\mathrm{C}_{7} \mathrm{H}_{15}$. radicals (pathway 14) also because the unsaturated sites enhance of $\mathrm{C}-\mathrm{C}$ bond cleavage. $\mathrm{CH}_{2}=\mathrm{CH}-\mathrm{CH}=\mathrm{CH}_{2}$ then combines with $\mathrm{C}_{2} \mathrm{H}_{4}$ (pathway 16), and generates benzene and $\mathrm{H}_{2}$ through the dehydrogenation reaction (pathway 17). The $\mathrm{C}_{7} \mathrm{H}_{15}$. radical decomposes through ethylene elimination and then generates $\mathrm{C}_{2} \mathrm{H}_{4}$ and $\mathrm{C}_{3} \mathrm{H}_{7}$. radicals (pathway 18).

Comparing Figure 22 with Figure 23, it is obvious that the principal decomposition pathways of oleic-type triglyceride and linoleic-type triglyceride during pyrolysis are basically the same, except pathways 14-18, and the standard reaction enthalpies of the same type of reaction are also consistent. The $\mathrm{C}_{7} \mathrm{H}_{10}$. radical, which is attributed by $\mathrm{C}-\mathrm{C}$ bond cleavage has a higher degree of unsaturation, 
so it could not combine with $\mathrm{C}_{2} \mathrm{H}_{4}$ and then generate benzene and $\mathrm{H}_{2}$ through the dehydrogenation reaction. This verifies the results that the $\mathrm{H}_{2}$ concentration in overheated camellia insulating oil is higher than that in FR3.

\section{Conclusions}

The present work focuses on the dissolved gas analysis of vegetable insulating oil. The experiment and analysis results are summarized as follows:

(1) The main fault gases of two types of vegetable insulating oils with different chemical compositions under the thermal faults are obtained. In the mineral insulating oil, the main gas composition of overheating is $\mathrm{CH}_{4}$, while in FR3, it is $\mathrm{C}_{2} \mathrm{H}_{6}$, and in camellia insulating oil, the main gas compositions are $\mathrm{H}_{2}$ and $\mathrm{C}_{2} \mathrm{H}_{6}$. The existence of insulating paper significantly increases the amount of $\mathrm{CO}$ and $\mathrm{CO}_{2}$ dissolved in oil.

(2) The percentage of main dissolved gases increase regularly with the increase in temperature. In mineral oil, the percentage of $\mathrm{CH}_{4}$ and $\mathrm{C}_{2} \mathrm{H}_{4}$ increase as the temperature increases. In FR3 oil, the percentage of $\mathrm{C}_{2} \mathrm{H}_{6}$ also increases as the temperature increases. In camellia oil, the percentage of $\mathrm{H}_{2}$ increases while the percentage of $\mathrm{C}_{2} \mathrm{H}_{6}$ fluctuates with the increase of temperature.

(3) A large amount of $\mathrm{C}_{2} \mathrm{H}_{2}$ is generated under high energy electrical breakdown both in vegetable insulating oil and mineral insulating oil, which shows that the main dissolved gas under electrical breakdown in vegetable insulating oil and mineral insulating oil are the same.

(4) The three-ratio method, graph representation method, Duval Triangle 1, and Duval Pentagon method are not applicable to diagnose thermal faults in vegetable insulating oils. When these interpretation methods are applied to interpret data of simulated electrical faults in vegetable insulating oils, the graph representation method, Duval Triangle, and Duval Pentagon methods can correctly diagnose electrical breakdown. Moreover, the modified Duval Triangle method based on Duval Triangle 3 is used to diagnose the thermal and electrical fault of FR3 oil and camellia oil through redefining zone boundaries of Duval Triangle 1 and obtains more accurate diagnostic results.

(5) The gas formation mechanisms of FR3 oil and camellia oil under thermal stress are studied in this paper. The principle decomposition pathways of these two type of oils have been analyzed, and the different generation mechanisms of gases in FR3 oil, camellia oil, and mineral oil have been interpreted by means of unimolecular pyrolysis simulation and reaction enthalpies calculation.

Acknowledgments: The authors acknowledge National Science Foundation of China (No. 51425702 and No. 51321063) and the National "111" Project (B08036). We also appreciate National Supercomputing Center in Shenzhen for providing the computational resources and Gaussian (Gaussian 09 D01: Gaussian, TCP-Linda, GaussView).

Author Contributions: The article was finished by a team, every author took part in the whole work. Quan Zhou and Jian Li designed and organized the experiment. Chenmeng Xiang carried out the experiments with Zhaotao Zhang, analyze the test results with Danqing Huang and Haoyong Song, make unimolecular simulation and write this paper.

Conflicts of Interest: The authors declare no conflict of interest.

\section{References}

1. Zheng, Y.B.; Sun, C.X.; Li, J.; Yang, Q.; Chen, W.G. Entropy-based bagging for fault prediction of transformers using oil-dissolved gas data. Energies 2011, 4, 1138-1147. [CrossRef]

2. Bakar, N.A.; Abu-Siada, A.; Islam, S. A review of dissolved gas analysis measurement and interpretation techniques. IEEE Electr. Insul. Mag. 2014, 30, 39-49. [CrossRef]

3. Sun, H.C.; Huang, Y.C.; Huang, C.M. A review of dissolved gas analysis in power transformers. Energy Procedia 2012, 14, 1220-1225. [CrossRef] 
4. Kim, S.-W.; Kim, S.-J.; Seo, H.-D.; Jung, J.-R.; Yang, H.-J.; Duval, M. New methods of DGA diagnosis using IEC TC 10 and related databases Part 1: Application of gas-ratio combinations, IEEE Dielectrics and Electrical Insulation. IEEE Trans. Dielectr. Electr. Insul. 2013, 20, 685-690.

5. Duval, M.; dePabla, A. Interpretation of gas-in-oil analysis using new IEC publication 60599 and IEC TC 10 databases. IEEE Electr. Insul. Mag. 2001, 17, 31-41. [CrossRef]

6. Duval, M.; Lamarre, L. The Duval pentagon-A new complementary tool for the interpretation of dissolved gas analysis in transformers. IEEE Electr. Insul. Mag. 2014, 30, 9-12.

7. Chen, W.G.; Chen, X.; Peng, S.Y.; Li, J. Canonical correlation between partial discharges and gas formation in transformer oil paper insulation. Energies 2012, 5, 1081-1097. [CrossRef]

8. Fofana, I. 50 years in the development of insulating liquids. IEEE Electr. Insul. Mag. 2013, 29, 13-25. [CrossRef]

9. Li, J.; Yao, S.H.; Du, B.; Yao, W. Analysis to principle problems and future prospect of research on vegetable insulating oils and their applications. High Volt. Eng. 2015, 2, 353-363.

10. Li, J.; Zhang, Z.T.; Grzybowski, S.; Zahn, M. A new mathematical model of moisture equilibrium in mineral and vegetable oil-paper insulation. IEEE Electr. Insul. Mag. 2012, 19, 1615-1622. [CrossRef]

11. Martin, D.; Lelekakis, N.; Wenyu, G.; Odarenko, Y. Further studies of a vegetable-oil-filled power transformer. IEEE Electr. Insul. Mag. 2011, 27, 6-13. [CrossRef]

12. IEEE Natural Ester Working Group. IEEE Guide for Acceptance and Maintenance of Natural Ester Fluids in Transformers; IEEE Std. C57.147-2008; Institute of Electrical and Electronics Engineers (IEEE): New York, NY, USA, 2008.

13. Martin, D.; Lelekakis, N.; Davydov, V.; Orarenko, Y. Preliminary results for dissolved gas levels in a vegetable oil-filled power transformer. IEEE Electr. Insul. Mag. 2010, 26, 41-48. [CrossRef]

14. Imad, U.K.; Zhongdong, W.; Cotton, I.; Northcote, S. Dissolved gas analysis of alternative fluids for power transformers. IEEE Electr. Insul. Mag. 2007, 23, 5-14. [CrossRef]

15. Wilhelm, H.M.; Santos, C.C.; Stocco, G.B. Dissolved gas analysis (DGA) of natural ester insulating fluids with different chemical compositions. IEEE Trans. Dielectr. Electr. Insul. 2013, 21, 1071-1078.

16. Muhamad, N.A.; Phung, B.T.; Blackburn, T.R. Dissolved gas analysis for common transformer faults in soy seed-based oil. IET Electr. Power Appl. 2011, 5, 133-142. [CrossRef]

17. Perrier, C.; Marugan, M.; Beroual, A. DGA comparison between ester and mineral oils. IEEE Trans. Dielectr. Electr. Insul. 2012, 19, 1609-1614. [CrossRef]

18. Iovalekic, M.; Vukovic, D.; Tenbohlen, S. Dissolved gas analysis of alternative dielectric fluids under thermal and electric stress. In Proceedings of the IEEE International Conference on Dielectric Liquids, Trondheim, Norway, 26-30 June 2011; pp. 1-4.

19. Duval, M. The duval triangle for load tap changers, non-mineral oils and low temperature faults in transformers. IEEE Electr. Insul. Mag. 2008, 24, 22-29. [CrossRef]

20. Duval, M.; Baldyga, R. Stray gassing of FR3 oils in transformers in service. In Proceedings of the 76th Annual International Doble Client Conference, Boston, MA, USA, 29 March-3 April 2009.

21. IEEE Interpretation of Gases Generated in Natural Ester and Synthetic Ester-Immersed Transformers Working Group. IEEE Guide for Interpretation of Gases Generated in Natural Ester and Synthetic Ester-Immersed Transformers; IEEE Std. C57.155-2014; Institute of Electrical and Electronics Engineers (IEEE): New York, NY, USA, 2014.

22. International Electrotechnical Commission (IEC). Mineral Oil-Impregnated Electrical Equipment in Service-Guide to the Interpretation of Dissolved and Free Gases Analysis; IEC Std. 60599; International Electrotechnical Commission (IEC): Geneva, Switzerland, 2007.

23. Cargill. Envirotemp FR3 Fluid. Available online: http://www.cargill.com/products/industrial/dielectricester-fluids/envirotemp-fr3/index.jsp (accessed on 1 February 2015).

24. Jovalekic, M.; Vukovic, D.; Tenbohlen, S. Gassing behavior of various alternative insulating liquids under thermal and electrical stress. In Proceedings of the IEEE International Symposium on Electrical Insulation, San Juan, Puerto Rico, 10-13 June 2012; pp. 490-493.

25. Kassi, K.S.; Fofana, I.; Meghnefi, F.; Yeo, Z. Impact of local overheating on conventional and hybrid insulations for power transformers. IEEE Trans. Dielectr. Electr. Insul. 2015, 22, 2543-2553.

26. Alencar, J.; Alves, P.; Craveiro, A. Pyrolysis of tropical vegetable oils. J. Agric. Food Chem. 1983, 31, $1268-1270$. [CrossRef] 
27. Schwab, A.; Dykstra, G.; Selke, E.; Sorenson, S.; Pryde, E. Diesel fuel from thermal decomposition of soybean oil. J. Am. Oil Chem. Soc. 1988, 65, 1781-1786. [CrossRef]

28. Wang, Z.; Yi, X.; Huang, J.; Hinshaw, J.V.; Noakhes, J. Fault gas generation in natural-ester fluid under localized thermal faults. IEEE Electr. Insul. Mag. 2012, 28, 45-56. [CrossRef]

29. Fofana, I.; Sabau, J.; Bussieres, D.; Robertson, E. The mechanism of gassing in power transformers. In Proceedings of the IEEE International Conference on Dielectric Liquids, Poitiers, France, 30 June-3 July 2008; pp. 1-4.

(C) 2016 by the authors; licensee MDPI, Basel, Switzerland. This article is an open access article distributed under the terms and conditions of the Creative Commons Attribution (CC-BY) license (http:/ / creativecommons.org/licenses/by/4.0/). 